\title{
FILOSOFÍA APLICADA EN CONTEXTOS DE COLONIALIDAD Y EMERGENCIA: EL CASO DE EUGENIO ESPEJO
}

\author{
SAMUEL GUERRA BRAVO \\ Pontificia Universidad Católica del Ecuador \\ sguerrab@puce.edu.ec
}

RECIBIDO: 12 DE MARZO DE 2010

ACEPTADO: 4 DE MAYO DE 2010

Resumen. En los contextos coloniales hispanoamericanos de los siglos XVI, XVII y XVIII, los indios y mestizos (que habían resultado de la unión de españoles e indígenas) estaban expulsados, no solo del ámbito de la racionalidad (y, por tanto, de la filosofía) sino del ámbito de lo humano como tal. El hecho poco común de que un colonizado se atreviera a educarse, a pensar, a valorarse a sí mismo y autoproclamarse filósofo adquiría significación ontológica, cognoscitiva, ética y política. Ser filósofo, invadir el ámbito de la razón, considerado privativo de la aristocracia chapetona y criolla, era un verdadero atentado contra el sistema, pero era a la vez el más glorioso modo de construirse como ser humano y como sujeto. Las vicisitudes de la vida, el pensamiento y la lucha de Eugenio Espejo por darse un estatuto humano y racional, extendible a todos, nos permiten ver el escabroso pero dignificante itinerario de un filósofo aplicado en una oscura y lejana colonia española del siglo XVIII. Espejo es un caso paradigmático de cómo la filosofía aplicada puede ayudar a clarificar los conflictos existenciales y conducir incluso a la paz interior a pesar de una vida trágica. Por ello, el artículo considera también que la Filosofía Aplicada, universal en tanto filosofía, adquiere ciertos rasgos particulares y específicos en contextos donde la "colonialidad del ser, del poder y del saber" estaba y está vigente. Allí, la filosofía aplicada ha cumplido y se ve abocada a seguir cumpliendo funciones humanistas, descolonizadoras y reivindicativas.

Palabras clave. Colonialidad, filosofía aplicada, educación, humanidad.

\begin{abstract}
In Hispanic American colonial contexts of the sixteenth, seventeenth and eighteenth centuries, indians and mestizos (which had resulted from the union of Spanish and Indian) were expelled, not just the scope of rationality (and thus, of philosophy) but the scope of the human as such. The unusual fact that an educated colonized dared to think, to value yourself and self proclaim philosopher acquired ontological significance, cognitive, ethics and politics. To be a philosopher, to invade the realm of reason, considered unique to the greenhorns and Creole aristocracy, was a real attack against the system, but was at once the most glorious way to build a human being and as a subject. The vicissitudes of life, thought and struggle of Eugenio Espejo for taking a humane and rational status, extended to all, allow us to see the rough itinerary but dignified
\end{abstract}


philosopher applied on a dark and distant eighteenth century Spanish colony. Espejo is a prime example of how applied philosophy can help clarify the existential conflicts and even lead to inner peace despite a tragic life. Therefore, the paper also considers the Applied Philosophy, while universal philosophy, acquired traits are specific contexts where the "coloniality of being, power and knowledge" was and is ongoing. There, applied philosophy has come and has no choice but to continue to meet human functions, decolonizing and vindictive.

Keywords. Colonity, philosophical practice, instruction, humanity

\section{Introducción}

La Filosofía Aplicada tiene principios generales y universales que emanan del hecho de que ella es, ante todo, filosofía. Pero hay, de hecho, contextos particulares y específicos que le dan un color regional y hasta local. Son estas particularidades las que permiten hablar, por ejemplo, de filosofía francesa, alemana o española, sin que por ello se ponga en riesgo los fundamentos de la filosofía en tanto tal. El carácter racional, la visión de totalidad, la rigurosidad y sistematicidad, el afrontamiento de los problemas acuciantes de su espacio-tiempo, el método y la búsqueda inclaudicable de la verdad han caracterizado a la filosofía en cualquier parte y en todo tiempo.

Bajo estos parámetros, este trabajo quiere exponer las líneas significativas de la vida y el pensamiento de Eugenio Espejo, un "ilustrado" americano de la segunda mitad del siglo XVIII, que desplegó su labor filosófica en la antigua colonia española denominada Real Audiencia de Quito, hoy Ecuador, Sudamérica. El objetivo es sistematizar los aportes de Espejo en torno a principios y temas que en su momento constituyeron la fuente de sentido para su pensamiento y acción. Tales principios están vinculados directamente a los problemas individuales y colectivos de deshumanización, desprestigio y calumnia que la Europa moderna desplegó sobre América y los americanos ${ }^{1}$, y que provocaron situaciones existenciales de desintegración identitaria, obnubilación en el pensar, autodesvalorización, deshistorización, conformismo, extranjerismo, racismo, etc., que se reflejaban tanto en las

\footnotetext{
1 Cf. Antonello Gerbi, La calumnia de América, Fondo de Cultura Económica, México, 1960, 681 ps.
} 
existencias individuales como grupales. Frente a conflictos existenciales de este tipo, Espejo realmente tiene mucho que decir.

\section{Biografía de Emilio Espejo y su relación con la Filosofía Aplicada}

Espejo nació en Febrero de 1747. Su padre, Don Luis de la Cruz y Espejo, fue hijo de un cantero de Cajamarca, vino a Quito al servicio del Fraile Betlemita P. José del Rosario y se desempeñó como cirujano (sangrador) en el Hospital de la Misericordia, administrado por los Betlemitas. Su madre, Catalina Aldaz, fue una mulata. Espejo fue, pues, un indio (en el peor de los casos) o un mestizo (en el mejor de los casos) de "vilísimo nacimiento" según los patrones sociales de la época. Él mismo consignará más tarde que "había nacido en el hospital, criándose en él" "2. Esta baja extracción social y su larga convivencia con la enfermedad, el dolor, la miseria, la ignorancia y la muerte le desarrollarán una "naturaleza muy sensible", capaz de percibir agudamente los problemas de la marginalidad y colonialidad. El pensador quiteño buscará superar sus determinaciones sociales con los únicos poderes a los que pudo acceder: la crítica y la sátira, el análisis, la reflexión y el discurso manejados como acción reivindicativa. En este proyecto, ciencia y filosofía modernas constituirán para él mecanismos de la razón aplicables tanto a la lastimosa situación de Quito de fines del siglo XVIII como a su propia re-generación humana.

Luego de la Escuela de primeras letras, Espejo estudió Artes o Filosofía en el Seminario de San Luis y Universidad de San Gregorio Magno, regentados por los jesuitas. Entró allí, al parecer, por influjo de su padre, cirujano de la Compañía, y no porque hubiera probado su limpieza de sangre: recurso obligatorio para el acceso a los colegios y universidades de entonces ${ }^{3}$. Bajo el influjo del P. Juan de Hospital, jesuita docto que impartió un curso de filosofía escolástica a pulso con los

\footnotetext{
${ }^{2}$ Eugenio Espejo, Reflexiones acerca de las Viruelas, Escritos de Espejo, Imprenta Municipal, Quito, 1912, vol. II, p. 510 .

${ }^{3}$ Años más tarde y, según lo sostienen algunos historiadores, Espejo organizó un expediente para probar su limpieza de sangre como requisito para ser nombrado Director de la Biblioteca pública de Quito, pero tal expediente no se ha encontrado hasta el día de hoy.
} 
sistemas científicos (Copérnico, Kepler, Galileo, Gassendi, Newton) y filosóficos (Bacon, Descartes, Leibniz, Hobbes, Magnin, Tosca) modernos, Espejo desarrolló su "genio dedicado a las observaciones físicas" ${ }^{4}$ y accedió a un horizonte de comprensión basado en la observación y experiencia que le permitiría superar el horizonte puramente especulativo de la escolástica.

Hasta entonces, la baja extracción social de Espejo no se había tornado conflictiva. Pero cuando "a los quince años (1762) deseó ardientemente ser conocido por bello espíritu y aunque logró las celebridades de los jesuitas (grados de Bachiller y Maestro de Filosofía), el vulgo lo despreció" 5 . Los estigmas de su "vilísima" extracción social, que solo lo habilitaban para los oficios manuales y ruines, entraron en conflicto con la "nobleza" del conocimiento y la razón, privativas de la aristocracia criolla y chapetona. A partir de entonces, Espejo vivirá situaciones existenciales marcadas por el rechazo y el desprecio de la aristocracia racista e ignorante.

Poco después estudiará medicina en la Universidad de Santo Tomás, regentada por los Dominicos, graduándose en 1767 sin las formalidades que tal grado implicaba: libreas, estandarte con escudo de armas del graduado y paseo por la ciudad. Entre 1767 y 1770 estudió además Derecho Civil y Canónico graduándose de Licenciado. En este último año también, Espejo se presentó ante el Cabildo de Quito al examen que le habilitaría para ejercer públicamente la profesión de médico, pero fue reprobado, no por falta de conocimientos, sino para que sus títulos y cartas de licencia no corriesen con el tinte denigrativo de haber "nacido en el hospital, criándose en él" ${ }^{6}$. Espejo practicó en el hospital durante dos años más y en 1772 volvió a presentarse al examen del Cabildo. Fue aprobado esta vez con la condición de que practicase un año más.

Hasta aquí, Espejo había estudiado "diversas facultades". Luego, presionado por la necesidad de "legitimar" su instalación en el ámbito de la "razón" se dedicará a "estudios más serios": estudios "clásicos" de la

\footnotetext{
${ }^{4}$ Espejo, Reflexiones..., p. 476.

${ }^{5}$ E. Espejo, La ciencia blancardina, Escritos de Espejo, Imprenta Municipal, Quito, 1912, vol. II, p. 334.

${ }^{6}$ Espejo, Reflexiones..., vol. II, p. 510.
} 
Biblia, Cicerón, Virgilio y Horacio ${ }^{7}$ que le van a permitir descubrir su aptitud para formar "lo que en lenguaje de los doctos se llama sátira y ha sido del gusto del público" 8 . Armado de la sátira, emprenderá en una vasta tarea crítica a través de obras que, además de sus contenidos específicos, tenían la intencionalidad de legitimar su derecho a la "razón", a la ciencia y al pensamiento ${ }^{9}$. Emprendió, pues, amparado en el pseudónimo, contra el sistema de enseñanza de la filosofía y la teología y, en general, contra el mal gusto, la ignorancia e insensatez reinante en Quito, a través de obras como El nuevo Luciano de Quito, Marco Porcio Catón, y, La ciencia blancardina (que circularon entre 1779 y 1781), con las que propuso "un mejorado sistema de conocimientos" que sirviera, además, como remedio "oportuno contra las rebeldes enfermedades de la indolencia y de la apoplejía quiteña en punto de letras" ${ }^{10}$. Las Órdenes religiosas que monopolizaban la educación y el clero quiteño constituyeron esta vez el blanco de la sátira y la crítica del mestizo quiteño. La respuesta de éstos fue alcanzar del Presidente de la Audiencia que nombrara a Espejo médico de una tropa acantonada en las riveras del Marañón, con el objeto de alejarlo de Quito. Espejo se vio obligado a huir de Quito, con poca fortuna, pues fue delatado, entregado y puesto en prisión en Riobamba. Para entonces, Espejo era ya "conocido en todo el Reino por su literatura", pero la imagen que la aristocracia había construido de él era la de un genio propenso a la sátira, de carácter soberbio, impetuoso, malignante y osado hasta lo sumo ${ }^{11}$, al que había que perseguir y mantenerlo a toda costa alejado de Quito.

Las epidemias que asolaban a Quito favorecieron el retorno de Espejo. El Cabildo le comisionó para que expusiera en un escrito sus reflexiones físicas, económicas, políticas y morales sobre la peste de viruelas: encargo que se le hiciera por "reputarlo filósofo instruido, y sujeto

\footnotetext{
${ }^{7}$ Cf. Espejo, La ciencia..., vol. II, p. 129.

${ }^{8}$ Espejo, La ciencia ..., vol. II, p. 333.

${ }^{9}$ Esto de legitimar su derecho a la razón criticando la razón existente parecería contradictorio, pero no lo es porque lo que hizo Espejo fue minar la racionalidad enferma y adormecida, vacía y ostentosa, y reemplazarla por "una nueva experiencia de la razón" basada en la solidez de los estudios, del pensamiento y de la responsabilidad cívica.

${ }^{10}$ Espejo, La ciencia..., vol. II, p. 296.

${ }^{11}$ Carta del Presidente José de Villalengua y Marfil al Virrey de Bogotá Dn. Francisco Gil y Lemos, del 3 de Junio de 1789; Archivo Histórico, Nacional de Bogotá, Miscelánea, t. 143, f. 1009-v.
} 
aficionado a cultivar la universal literatura" ${ }^{12}$. Su talante filosófico, acostumbrado a la observación y a la búsqueda de las causas últimas, le permitió identificar a los hacendados, que especulaban con el trigo, como los causantes de la insalubridad de Quito. La comprensión filosófica que Espejo muestra en "Reflexiones sobre las Viruelas" es la de un pensador y patriota que desde que logró "la luz de la razón, ha atendido solamente a la felicidad de la patria". Lo filosófico en Espejo es su método de abrir el mundo, por más que hable de cuestiones médicas, económicas, políticas o culturales. Por esta especial visión de su realidad extenderá sus críticas a los hospitales, monasterios, iglesias, y, sobre todo, a los "falsos médicos" que con su ignorancia empeoraban la calamitosa salud de Quito.

Las quejas de los falsos médicos y de los Betlemitas llegaron pronto a oídos del Presidente de la Audiencia, quien llamó a Espejo para reprenderlo y exigirle que rompiera su escrito o no hiciera uso de él. Nuestro mestizo apeló al criterio de personas juiciosas que ratificaron que "Reflexiones..." no contenía nada injurioso. La autoridad, sin embargo, había dispuesto una cercana vigilancia sobre Espejo. Ante esta situación, se vio nuevamente obligado a abandonar Quito, a principios de 1786, anunciado que viajaba a Lima, aunque en realidad nunca avanzó más allá de Riobamba y sus alrededores. Su "vagabundeo" por esos lares fue muy provechoso: asumió la defensa de los Curas de Riobamba que habían sido acusados por los cobradores de tributos de ser los causantes de la pobreza general de la Audiencia al promover la multiplicación de fiestas religiosas, lo cual, según aquellos, dejaba sin dinero a los indígenas para pagar los tributos a la corona española. Escribió entonces una "Defensa de los Curas de Riobamba" ${ }^{13}$ que le sirvió para realizar un lúcido y profundo análisis de la economía de la Presidencia de Quito.y para investigar a fondo los usos, costumbres, modos de vida y pensamiento de los indígenas, El rasgo verdaderamente distintivo de esta obra radica en el inmenso esfuerzo antropológico que desplegó Espejo para sacar a luz los rasgos humanos de quienes hasta entonces no eran hombres, sino, como

\footnotetext{
${ }^{12}$ Espejo, Reflexiones..., Escritos II, p. 363

${ }^{13}$ El título completo decía: "Representación de los Curas del Distrito de Riobamba hecha a la Real Audiencia de Quito, para impedir la fe que se había dado a un informe que contra ellos produjo Don Ignacio Barreto" (cobrador de tributos de esa zona).
} 
lo había señalado Bartolomé de las Casas dos siglos atrás, "menos que estiércol de las plazas". Esta fue una oportunidad para que Espejo volviera a sentir el peso de las amenazas, calumnias y atentados contra su vida, promovidos esta vez por la burocracia aliada con la "nobleza" riobambeña. Nuestro compatriota intentó neutralizar estos ataques escribiendo la obra más satírica que conocería el siglo XVIII quiteño: las "Cartas riobambenses", obra maestra de sátira, por sus alusiones, juegos de palabras, doble sentido de muchas expresiones, pintura de las costumbres, vuelo sarcástico, y enfrentamiento de dos espíritus opuestos: ilustración francesa y pietismo riobambeño.

Un sector del clero, la burocracia, los "malos médicos" y la aristocracia utilizarán a mediados de 1787 todos los recursos legales e ilegales para deshacerse de Espejo. El andamiaje acusatorio que estos sectores habían levantado en su contra iban desde las intrigas domésticas hasta la acusación de "ateísta y perturbador de la república", desde la afirmación de que si pasaba a Lima sería "capaz de promover la rebelión del Perú" hasta la acusación de haber sido el autor de la "infernal sátira La Golilla" que había circulado hacía unos seis años en Quito. Estas acusaciones hacían de Espejo un "reo de Estado" y "un delincuente". Se movilizó entonces la maquinaria legal para que el Presidente de la Audiencia se viese obligado a "hacer justicia seca" (ordenar su prisión y ejecución). En efecto, se le arrestó por segunda vez en Riobamba con el secuestro de todos sus papeles, se le trasladó ignominiosamente a Quito, se le instauró un juicio y, ante la sugerencia de los jueces de encontrar una transacción antes que una sentencia, el Presidente de la Audiencia le conminó a abandonar Quito. Espejo salió de esta ciudad a fines de 1787, esta vez rumbo a Bogotá.

María Chiriboga, la mujerzuela riobambeña de noble alcurnia aludida en "Cartas riobambenses..." y "otros de este jaez" consideraron que el destierro era poco castigo y pusieron inmediatamente un nuevo juicio a Espejo. El eje transversal de este nuevo juicio era la baja extracción social de nuestro personaje, subrayada esta vez por el mismo religioso Fr. José del Rosario, convertido ya en enemigo de Espejo. Este se defendió de los juicios que habían sido remitidos al Virrey de Bogotá y fue absuelto. Espejo aprovechó el tiempo y publicó en Bogotá un "Discurso a la Sociedad Patriótica La Escuela de la Concordia" con el que se 
inauguraría, una vez vuelto a Quito, la Sociedad literaria y económica, impulsada por la misma corona española, que buscaría el adelantamiento de la Audiencia en las ciencias y las artes, la agricultura y el comercio, la economía y la política. Espejo fue nombrado Secretario de la Sociedad y, en calidad de tal y como redactor único, promovió la circulación del Periódico "Primicias de la Cultura de Quito" con el que buscó concretar una estrategia cultural para la redención de la Audiencia. Espejo desplegó también, paralelamente, otras estrategias: una económica con "Memoria del corte de quinas" y "Voto de un Ministro Togado", y, una ideológica con el "Primer Sermón de Santa Rosa", de 1793. Con ellas pretendía superar sus enfrentamientos solitarios con las clases altas e involucrarlas, más bien, en el proyecto restaurador. Sin embargo, sus antiguos enemigos y nuevas supuestas "ofensas" al público echaron a perder el proyecto del periódico, del que solo aparecieron siete números entre enero y marzo de 1792. Pero el golpe mortal vino de Carlos IV, Rey de España, mediante Cédula Real de 11 de Noviembre de 17931, con la cual desaprobaba la Sociedad Patriótica. Esta desilusionante realidad le va a empujar a Espejo a ideas, no ya de restauración, sino de transformación de la patria.

El 21 de Octubre de 1794 fueron colocadas en las cruces de la ciudad unas "banderitas" de tafetán colorado con la inscripción, por un lado, "Liberi Sto. Felicitatem et gloriam consecunto" y, por el otro, "Salva cruce" ${ }^{14}$. Igualmente, en las puertas del Cabildo secular y en otros parajes habían aparecido diversos "pasquines" y, un mes más tarde, otros "papeles" dirigidos todos, según el Presidente de la Audiencia, a "alucinar a la plebe, procurando su sublevación" ${ }^{15}$. Por sus antecedentes y por diálogos "poco conformes a los derechos de S. M." con su hermano Juan Pablo que, gracias a una indiscreción, llegaron a oídos del Presidente de la Audiencia, los hermanos Espejo fueron puestos en prisión a inicios de 1795. Juan Pablo, que era cura, pasó a un tribunal eclesiástico y Eugenio fue juzgado por un tribunal civil que agitó las anteriores causas legales sobre "La Golilla" y sobre las "Cartas Riobambenses" con el objeto de mantener en prisión a Espejo. Aunque lo

\footnotetext{
14 "Sed libres. Conseguid la felicidad y la gloria". "Salvos por la cruz"

${ }^{15}$ Carta del Presidente de la Real Audiencia de Quito, Don Luis Muñoz de Guzmán, al Virrey de Bogotá, Don Joseph de Ezpeleta. Transcripción en Archivo Flores, Pontificia Universidad Católica del Ecuador (PUCE), Quito, Carpeta de documentos sobre Espejo.
} 
más probable es que Espejo fuera el mentalizador de las "banderitas", "pasquines" y "papeles", no se pudo comprobar su culpabilidad. Se lo liberó en Marzo de 1795 y se lo volvió a apresar un día después, a raíz de los "pasquines de Cuenca" aparecidos el 21 de Marzo de ese mismo año. Incomunicado, confinado en una celda húmeda y privado de libros y materiales para escribir, Espejo contrajo pronto una disentería que lo minó paulatinamente. Saldría de la cárcel, meses después, solamente para morir, hecho que ocurrió el 26 ó 27 de Diciembre de $1795^{16}$.

\section{Marco general del pensamiento de Espejo}

El descubrimiento de América de fines del siglo XV y la conquista del siglo XVI constituyen episodios que marcaron nuevos rumbos históricos para América, España y Europa en todos los órdenes de la existencia. Fue el hecho inaugural de una nueva época, una nueva cosmovisión y una nueva ciencia de la naturaleza. Entre los argumentos para justificar la conquista estaban la incorporación de nuevas tierras y nuevos vasallos al Reino de España y la difusión de la fe cristiana en tierras de infieles. Estos objetivos, sin embargo, pronto fueron suplantados por la ambición del oro y las riquezas que encontraron en América. Bartolomé de las Casas, un conquistador que, al constatar la "destrucción" que los españoles empezaban a sembrar en América, se "convirtió" y dedicó su vida a la defensa de los indígenas, describió la verdadera y última razón de la conquista en estos términos:

Dos maneras generales y principales han tenido los que allá han pasado que se llaman cristianos en extirpar y raer de la haz de la tierra a aquellas miserandas naciones. La una, por injustas, crueles, sangrientas y tiránicas guerras. La otra, después que han muerto todos los que podrían anhelar o sospirar o pensar en libertad, o en salir de los tormentos que padecen..., oprimiéndolos con la más dura, horrible y áspera servidumbre en que jamás hombres ni bestias pudieron ser puestas...

\footnotetext{
${ }^{16}$ Como colofón supremo, el indio o mestizo que al nacer había sido inscrito en el "libro de españoles", al morir fue inscrito en el "libro de indios, negros y todas clases", folio 147, de la Iglesia de El Sagrario.
} 
La causa por la que han muerto y destruido tantas y tales e tan infinito número de ánimas los cristianos ha sido solamente por tener por su fin último el oro y henchirse de riquezas en muy breves días e subir a estados muy altos e sin proporción de sus personas, conviene a saber, por la insaciable cudicia e ambición que han tenido, que ha sido mayor que en el mundo ser pudo, por ser aquellas tierras $\tan$ felices e tan ricas, e las gentes tan humildes, tan pacientes e tan fáciles de subjectarlas; a las cuales no han tenido más respecto ni dellas han hecho más cuenta ni estima (hablo con la verdad por lo que se y he visto todo el dichoso tiempo), no digo que de bestias (porque pluguiera a Dios que como a bestias las hubieran tractado y estimado), pero como y menos que estiércol de las plazas" ${ }^{17}$.

¿Qué significó para el indígena americano, desde un punto de vista filosófico, quedar reducido a "menos que estiércol de las plazas"? Significó, sin más, una expulsión del ámbito de lo humano, de lo racional, de lo espiritual. El "encuentro" original fue inmediatamente un "desencuentro", una imposición violenta, un sometimiento, una "servidumbre". Para conquistarlos se dudó si los indígenas eran hombres, si tenían alma racional, si eran hijos de Dios ${ }^{18}$. Para someterlos sin remordimientos se echó mano de la doctrina aristotélica de la "esclavitud natural" 19 . Ocurrió, en suma, una degradación ontológica que no significaba el paso del ser al no-ser, sino la negación a los indígenas de su condición de sujetos y su transformación en objetos. Ocurrió un asesinato ético-político que transformó a los indígenas, de fines en sí mismos, en medios para los objetivos del conquistador. Ocurrió, en general, una deshumanización, una cosificación del indígena americano, de sus culturas y religiones. Esto era tan obvio y tan contrario a los principios políticos y religiosos que los Reyes de España empezaron a emitir desde

\footnotetext{
${ }^{17}$ Bartolomé de las Casas, Brevísima relación de la destrucción de las Indias, Ediciones Orbis, Barcelona, 1986, p. 52.

18 "Estos ¿no son hombres? ¿No tienen ánimas racionales? ¿no sois obligados a amallos como a vosotros mismos" fueron las palabras de Antonio de Montesinos, sacerdote dominico, en el sermón de un domingo de 1511. Cf. Lewis Hanke, El prejuicio racial en el nuevo mundo. Aristóteles y los indios de Hispanoamérica, Sep/Setentas, México, 1974, p. 39.

19 John Major, profesor escocés en Paris, fue el primero en utilizar la doctrina aristotélica de la esclavitud natural en 1510. En 1519 , en un debate en presencia del Rey Carlos V entre Juan Quevedo, Obispo de Darien, y Bartolomé de las Casas, el primero apeló a la tesis de La Política de Aristóteles para justificar la conquista. Más tarde, en el famoso debate de Valladolid (1550-1551) entre el "humanista" Ginés de Sepúlveda y el ex encomendero y ahora sacerdote Bartolomé de las Casas, aquel volvió a fundamentar la "legitimidad" de la conquista en el pensamiento de Aristóteles. Cf. L. Hanke, El prejuicio racial..., p. 39 y ss.
} 
principios del siglo XVI, leyes que protegieran a los indígenas. Pero la ambición y el interés de los conquistadores encontró una forma de eludir el cumplimiento de la ley con aquella expresión consuetudinaria, "las leyes se acatan pero no se cumplen", que reflejaba bien la indefensión en la que se encontraban los indígenas respecto de los conquistadores.

La descarnada descripción de Las Casas sobre la "destrucción de las Yndias Occidentales" pone de relieve la alienación total ocurrida con el indígena americano, el punto cero antropológico desde el que el americano deberá emerger en una lucha por re-constituirse como sujeto y ser humano, que aún no acaba. La descripción de Las Casas no fue una queja, sino una denuncia, es decir el paso primero en la re-constitución ontológica, antropológica, ética y política del americano de entonces y del actual latinoamericano. Las Casas inauguró entonces una tendencia de pensamiento humanista y reivindicativo, un tipo de filosofía aplicada, que representa lo más auténtico y peculiar del pensamiento latinoamericano desde el siglo XVI en adelante. En esa línea se ubicó Eugenio Espejo, nuestro genial mestizo que, dentro de las determinaciones de su época y con los recursos que encontró en la propia historia y en las tendencias filosóficas de su tiempo, luchó por la reivindicación del americano, de su realidad histórica, de su cultura y de sí mismo ${ }^{20}$.

Se entiende mejor ahora que los "temas" del pensamiento de Espejo sean la reforma de la educación y del pésimo gusto de los quiteños, la revalorización del indígena, la salud pública, la crítica a las ambiciones de los hacendados y cobradores de tributos, la afirmación de lo "quiteño" y del "quiteñismo", la necesidad de una nueva experiencia de la razón, la posibilidad de una "patria" propia, la oportunidad de un nuevo sistema político: temas que involucraban claramente una visión humanizadora y reivindicativa del indígena americano y de las nuevas realidades sociales que habían surgido a raíz de la conquista: mestizos (que resultaron de la

\footnotetext{
${ }^{20}$ Podríamos visualizar esta línea de pensamiento reivindicador y humanista a través de los siguientes autores y obras: Bartolomé de las Casas: "Brevísima relación de la destrucción de las Indias Occidentales" (1552); Antonio de León Pinelo: "El paraíso en el Nuevo Mundo" (1650); Eugenio Espejo: "Primicias de la Cultura de Quito" (1792); Simón Bolívar: "Carta de Jamaica" (1815); Simón Rodríguez: "Las sociedades americanas de 1826"; Juan Bautista Alberdi: "Ideas para presidir a la confección del Curso de Filosofía Contemporánea" (1840); Francisco Bilbao: "El Evangelio Americano" (1864); José Martí: "Nuestra América" (1891); José Lezama Lima: "La expresión americana" (1969); Arturo A. Roig: "Ética del poder y moralidad de la protesta. La moral latinoamericana de la emergencia" (2002).
} 
fusión entre españoles e indígenas) y criollos (hijos de españoles nacidos en América). Estos temas, que se imponían al pensamiento como una fundamental necesidad de humanización (verdadero "a priori antropológico"), le permitieron al mestizo Espejo desplegar tesis que no eran una gratuita impugnación al sistema vigente, sino una lucha y un esfuerzo intelectual y político por la subjetivación, la racionalidad, la historicidad, la empiricidad, la libertad, la dignidad, la gloria y la felicidad.

\section{Los "principios" de su filosofía}

Desde el punto de vista de la filosofía en general, la necesidad fundamental que atraviesa la historia del americano de entonces y del actual latinoamericano, desde el siglo XVI hasta el día de hoy, es el de nuestra re-constitución humana frente a las diversas formas de cosificación, marginación y exclusión que, de manera expresa o tácita han sido impuestas por los sucesivos sistemas coloniales. Un filósofo latinoamericano, Arturo A. Roig, ha definido esta necesidad de humanización como un verdadero "a priori" formulado en cuatro principios $^{21}$ :

- principio de perseverancia en el ser (Conatus: Spinoza): a priori ontológico,

- principio de auto y heterorreconocimiento (Hegel): a priori antropológico,

- principio de la naturaleza intrínseca del valor del ser humano (Marx): a priori ético-axiológico,

- principio del "duro trabajo" de la subjetividad o de la emergencia de los oprimidos (Antígona: Sófocles, Calibán: Shakespeare): a priori éticopolítico,

\footnotetext{
${ }^{21}$ Este a priori de carácter antropológico contrasta con el a priori de carácter epistemológico desplegado por Kant en Europa Cf. Ética del poder y moralidad de la protesta. La moral latinoamericana de la emergencia, Universidad Andina Simón Bolívar- Corporación Editora Nacional, Quito, 2002, p. 78.
} 
Desde el punto de vista de una filosofía aplicada, esclarecedora, humanista y reivindicativa, tales principios responden enteramente a nuestras necesidades históricas y antropológicas de identidad, afirmación, revalorización, ó, como diríamos ahora, a necesidades de autoconciencia, autonomía, soberanía, interdependencia, interculturalidad, visión planetaria y solidaridad cósmica, que, transformadas en "principios", encuentran formas de expresión y realización en el asesoramiento, orientación o consultoría filosófica, entendida como práctica discursiva liberadora ${ }^{22}$.

Eugenio Espejo, en el contexto de la segunda mitad del siglo XVIII quiteño, convirtió estos principios en auténticas "prácticas", no solo crítico-discursivas, sino ético-políticas, dirigidas a la reforma, restauración y transformación de la "patria". Paralelamente, Espejo buscaba una superación del sistema colonial deshumanizante, mediante la revalorización y dignificación de los sectores sociales "emergentes" de su tiempo: indígenas, mestizos, criollos. Aquella lucha era necesaria para que fuera posible su propia visualización y afirmación como sujeto capaz de moverse como pez en el agua en un ámbito del que estaba excluido por el racismo y los prejuicios de su época: el de la razón, el conocimiento, la filosofía y la ciencia.

Digamos dos palabras sobre cada uno de los principios que, utilizados como "prácticas discursivas" para una re-humanización emergente ${ }^{23}$, funcionan a la vez como categorías de comprensión: subjetivación, racionalidad, historicidad, contextualización, empiricidad, dignidad, libertad, gloria, felicidad.

Subjetivación: re-constitución del americano como sujeto de derechos y fin en sí mismo. La filosofía, aplicada a situaciones históricoantropológicas concretas, piensa las condiciones para una superación de la alienación ocasionada por la conquista y colonización españolas y,

\footnotetext{
${ }^{22}$ Cf. Samuel Guerra Bravo, La emergencia del espíritu. Ejercicios espirituales anti-imperialistas, Editorial Friends, Quito, 2009, ps. ......

${ }^{23}$ Preferimos la expresión "re-humanización emergente" a la de "humanismo ilustrado" que se ha usado para aludir a estos mismos procesos: La primera coloca como referencia a los procesos de nuestra propia realidad e historia, la segunda toma como referencia a la ilustración europea. Lo de "emergente" debe tomarse en dos sentidos: como algo "urgente" (al modo de los hospitales), que no puede ser postergado, y, como algo que brota y emerge desde nuestro mundo de necesidades e imperativos históricos: nuestra "verdad" (aletheia) en sentido griego.
} 
hoy, por los sistemas de marginación y exclusión aún vigentes. En "Defensa de los curas de Riobamba", Espejo señala que a los "infelices indios" se les tiene "por poco menos que bestias respecto de la razón y por poco menos que idólatras respecto de la piedad" ${ }^{24}$, pero que eso es desconocer totalmente su "genio y carácter". Expulsados del ámbito de lo humano, los indios no eran más que unos miserables "siervos" a quienes se les atribuía una imbecilidad connatural que los convertía en vagos, rústicos, salvajes y borrachos, como lo demostraba (según los conquistadores y colonizadores) su carácter, costumbres, danzas y hasta las fiestas religiosas que hacían. “¿Por qué los indios han de merecer, se pregunta Espejo, que pensemos siniestramente de todas sus prácticas e intenciones? Ellos son racionales, afirma, como todos los hombres: cristianos como todos los que abrazan el evangelio; hermanos nuestros, como lo son entre sí todos los hijos de Adán; y, por lo mismo, dignos de que los tratemos con caridad en obras, palabras y pensamientos" ${ }^{25}$. Y refiriéndose a la acusación común de imbecilidad y rusticidad de los indios, en un verdadero grito re-humanizador afirma: "la imbecilidad de los indios no es imbecilidad de razón, de juicio ni entendimiento, es imbecilidad política, nacida de su abatimiento y pobreza, semejante a la que, con la más villana adulación, manifestaba el Senado a presencia de Tiberio, que, conocedor cruel de ella, por ella, le despreciaba con estas palabras: servum pecus. Así, lo que tienen los indios es timidez, cobardía, pusilanimidad, apocamiento, consecuencias ordinarias en las naciones conquistadas... Querer suponer a los indios rústicos, salvajes y divorciados de la común luz natural, prontos por eso para hacer fiestas sin discernimiento, elección ni gusto, acerca de ellas, es el error de gentes que no saben su idioma, sus usos y costumbres, y es un absurdo político, filosófico y aun teológico, el mayor que pueda escogitarse, y es un oprobio de la humanidad pensar así" 26.

Racionalidad: A la razón contemporánea puede parecer increíble que uno de los atributos metafísicos del ser humano, su razón, pueda ser utilizado y manipulado como un recurso de dominio. Pero el sistema colonial español y en general todos los sistemas coloniales se basaron y

\footnotetext{
${ }^{24}$ E. Espejo, Defensa..., Escritos III, p. 98.

${ }^{25}$ E. Espejo, Defensa..., Escritos III, p. 127.

${ }^{26}$ E. Espejo, Defensa ..., Escritos III, p. 225.
} 
se basan hasta el día de hoy en una especie de segregación racional que margina a los pueblos colonizados del conocimiento, la ciencia, la técnica, la creatividad, la iniciativa. Este fue el caso de las colonias hispánicas en el contexto del siglo XVIII, al punto que el acceso y posicionamiento en el ámbito de la razón y el pensamiento, de la filosofía, la teología, la ciencia natural e incluso la ética aplicada constituyeron, como en el caso de Eugenio Espejo, verdaderas luchas por la humanización, subjetivación, autoconciencia, autovaloración y autoafirmación. De tal manera que no solo funcionaba el prejuicio racial, sino una verdadera expulsión del nivel de la racionalidad, pues el colonizado, por principio, sea indio o mestizo, estaba condenado a actividades manuales y no a tareas del pensamiento, privativas de los chapetones y criollos ${ }^{27}$.

Historicidad: reconocimiento de los indígenas como seres reales, históricos, temporales, situados, con modos de ser pertinentes y concretos, que colocan a los sometidos o colonizados más allá o más acá (en la historia) de la abstracta condición metafísica de "animales racionales". La deshistorización de los sujetos es, justamente, no solo un

\footnotetext{
${ }^{27}$ Véase esta perla de lo que venimos diciendo: "la juventud distinguida, después de dos o tres años de Gramática... pasa al estudio de las ciencias mayores como son la filosofía..., la teología, las leyes...; la gente vulgar por su naturaleza dada al ocio y a la pereza, ejercita con honra y habilidad la pintura y escultura y aunque solo se muestra excelente en imitar y sacar copias, sin embargo usa maravillosamente el arte. Los otros empleos que se juzgan vilísimos, se hallan en manos de los indios a los cuales la pereza les es congénita y familiar; a pesar de esto hacen maravillas y pasma ver su trabajo tan perfecto sin dirección y sin instrumento; cuanto ven lo imitan y solo les falta idea para inventar": Relación inédita de la Ciudad de Quito en el Perú, en Gaceta Municipal, Año XIX, № 77, Quito, Agosto de 1934, p. 33. El pensamiento, las ciencias y la creatividad que requieren de habilidades para pensar estaban reservados para "la juventud distinguida", las artes y oficios manuales que solo requieren de habilidades para "imitar y sacar copias" estaban destinados para la "gente vulgar", es decir para los colonizados. Al fondo de esta forma de concebir el uso de las capacidades racionales funcionaba una distinción metafísica entre señores y siervos, entre hombres y subhombres. La razón era de los señores; las manos, de los siervos. El pensar era de los chapetones; el trabajo, de los indios o mestizos. El logos era de los opresores; el pathos, de los oprimidos. El espíritu era de las clases sociales altas; la naturaleza, de las clases sociales bajas. La ciencia era de los conquistadores; las artes y oficios de los conquistados. ¿Puede extrañar acaso que Hegel haya colocado a América fuera del ámbito del Espíritu y la haya recluido en el ámbito de la Naturaleza y de una futuridad sin actualización? ¿Cómo no comprender mejor ahora las tribulaciones que debió vivir Francisco Eugenio de Santa Cruz y Espejo, indio o mestizo de "vilísimo nacimiento" que estudió subrepticiamente filosofía en la Real y Pontificia Universidad de San Gregorio Magno, dirigida por los jesuitas y exclusiva de la nobleza criolla, que invadió por eso mismo un estrato ajeno a su condición social y se apropió de capacidades y habilidades racionales privativas de chapetones y criollos?
} 
modo de someter a los cuerpos sino también a las almas, a las mentes, a los espíritus, a las culturas. Espejo lo sufría en carne propia y sabía que una forma de luchar por la historicidad era la revalorización de la realidad y las culturas, del arte y del pensamiento, del buen gusto y el bello espíritu. Pero que eso lo planteara un indio en el Quito esclerótico y racista de fines del siglo XVIII, sonaba más a un atentado que a una aspiración laudable.

Contextualización: los seres humanos, racionales e históricos, deben ser entendidos dentro de un determinado entorno o contexto de carácter físico, social, político, cultural y lingüístico. Sacarlos de esas determinaciones y ubicarlos en marcos de referencialidad abstractos o extranjeros constituía y constituye un mecanismo de ocultamiento (para los demás y para sí mismos), invisibilización, sometimiento y exclusión. El hecho de entender a los indios en su contexto natural e histórico, sin difuminarlos en marcos especulativos y metafísicos, como lo hizo Espejo, constituía evidentemente una forma de volverlos visibles, pensables y valorables por sí mismos.

Empiricidad: la existencia de los seres humanos se manifiesta en la experiencia de sí mismos, en su identidad, costumbres y valores. El mecanismo español de destruir los modos de ser, costumbres, organización civil, política y religiosa de los indígenas americanos era un modo de sacarlos de su mundo de experiencia y sentido para convertirlos en mera fuerza de trabajo, animales de carga, esclavos sin alma, objetos a la mano. Los alegatos a favor de los indígenas que Eugenio Espejo desarrolla en "Defensa de los Curas de Riobamba" presentan siempre su lado experiencial, vital, cotidiano, como contraparte a los marcos y definiciones absolutistas del sistema imperial español.

Dignidad: condición de los seres humanos que son y se tienen como fines en sí y no como medios al servicio de otro, que los somete y esclaviza. Al emplear la filosofía para re-constituir el significado y sentido humano de los indígenas, Espejo desarrolla condiciones también para una reivindicación de su dignidad, capacidad, gravedad y decoro. La dignidad era y es un principio de naturaleza intrínseca al ser humano, que es avasallado por los sistemas coloniales. Entonces y hoy, la reivindicación de la dignidad humana, su defensa y florecimiento, constituyen signos de re-humanización, autoposesión, autonomía y 
autarquía: justo las condiciones de lo humano que de lograrse, aún en el plano individual, constituye de hecho una fisura para los sistemas de dominio.

Libertad: condición natural de los no sometidos o esclavizados, que emana de la propiedad de sí mismos, la cual les faculta a obrar de una manera u otra, o no obrar, siendo de ese modo responsables de los actos con los que organizan su existencia. Los indios americanos conquistados por España y todos los que padecen colonialidad hoy en cualquier parte del planeta, están impedidos o limitados en el ejercicio de esta facultad natural, humana, cívica y política. "iSed libres!” fue la exhortación de Espejo a sus compatriotas que sintetizaba no solo un anhelo político sino una necesidad de reivindicación como seres humanos y sujetos históricos. La libertad de la que hablaba nuestro mestizo no era una libertad abstracta, sino la concreta y palpable que surgiría de la ruptura con la economía mercantilista, la política regalista, la sociedad racista: una libertad, en fin, que condujera a la gloria y a la felicidad.

Gloria: cualidad típica de la ilustración europea que Espejo la americaniza y la entiende como un rango o como un estado propio de los seres humanos, coherente con su condición de racionales, capaces de o para organizarse y darse un destino. De esta condición podía derivarse una cierta reputación, fama y honor ligado a las buenas acciones o realizaciones como la lucha por la libertad y la dignidad. En el contexto del siglo XVIII, la gloria era un objetivo que podía justificar acciones de independización o liberación. Tal el caso, por ejemplo, de la admonición que constaba en las "banderitas" colocadas en las cruces de Quito en 1794: Felicitatem et gloriam consecunto (conseguid la felicidad y la gloria).

Felicidad: aunque es una categoría que viene desde la filosofía griega, en el contexto quiteño y americano del siglo XVIII aludía al estado de ánimo que podía seguir a la rehumanización de los indígenas, a su conquista de la razón, al logro de la restauración o transformación de la patria. La felicidad fue aludida expresamente en las "banderitas" con las que Espejo, su posible mentalizador, quería que los quiteños percibieran los objetivos de su redención como seres humanos y como país. 


\section{Espejo y un caso práctico de vida examinada.}

Espejo fue un caso paradigmático en el que la filosofía y su aplicación no solo sirvió a la causa de los indígenas, mestizos y criollos, sino ante todo a la re-constitución de sí mismo como ser humano, como sujeto. ¿Cuáles fueron las prácticas filosóficas que, en un contexto de colonialidad, le sirvieron a Eugenio Espejo para re-constituirse a sí mismo, examinar sus conflictos existenciales y diseñar estrategias de humanización, supervivencia y reivindicación? ¿Guardan algún paralelismo aquellas prácticas con las que la actual Filosofía Aplicada puede llevar adelante a través del asesoramiento, orientación o consultoría filosófica en contextos similares?

Ya hemos señalado que las situaciones existenciales contra las que luchó Espejo a lo largo de su vida fueron la deshumanización, marginación, desvalorización, racismo y desprecio, que las sufrió en carne propia. ¿Cómo hizo nuestro mestizo para superar la filosofía tradicional, especulativa y metafísica, con los recursos de una filosofía humanizadora, reivindicativa y revalorizadora? ¿Qué mecanismos de subjetivación le sirvieron para re-constituir su condición de ser humano, valioso en sí mismo? ¿Qué pautas podemos encontrar en el pensamiento de Espejo para una re-constitución existencial, ética y axiológica en contextos de colonialidad y emergencia? ¿Pueden tales pautas servir de referente para la orientación a consultantes en contextos donde sobreviven formas de dominio, degradación ontológica, asesinato ético, marginación, exclusión, rechazo y desprecio?

\section{Filosofía aplicada a nivel individual}

Frente a la deshumanización generada por el sistema de colonialidad, tal como éste estaba organizado en su tiempo, Espejo desarrolló, entre otras, las siguientes estrategias de humanización:

El "bello espíritu" y "las celebridades de los jesuitas": el genio intuitivo de Espejo le puso de manifiesto que una forma de humanización era el cultivo de sí y el estudio, que le permitirían alcanzar las celebridades de los jesuitas. Alcanzó tales "celebridades" y, aunque el vulgo le despreció, comprendió claramente que el ámbito del 
pensamiento, de la cultura y de la razón constituían lo específicamente humano que debía conquistar. Y, de hecho, en ese ámbito se movió toda su vida, aunque toda su vida también sufrió el rechazo de quienes solo vieron de él su condición social inferior y no su aptitud para la razón y el conocimiento, la filosofía y la ciencia natural.

El "arte de esconderse": consistía en ocultarse para lograr que los "satisfechos y presumidos de doctos" pensaran mal de sus alcances, conocimientos y literatura. Esa práctica le permitía, como estrategia de afirmación, confrontar interiormente lo que los otros sabían con sus conocimientos, que cada vez eran más vastos y escogidos.

"Otros estudios más serios": Espejo, además de filosofía, medicina y derecho civil y canónico, estudió a los clásicos. El estudio formativo de Cicerón, Virgilio, Horacio, la Biblia, etc, le dio las bases para un humanismo reflexivo. Esta maduración científica y humana le proporcionaba, frente al desprecio de los "lastimosos sabindojos", una conciencia de su propia dignidad y valor, así como del posible significado de su existencia en el contexto en que debía vivir.

Una "nueva experiencia de la razón": el Espejo maduro y crítico, capaz de cuestionar el estado de cosas, entiende que las posibilidades de subjetivación pasan por una nueva experiencia de la razón que, en el contexto del Quito de entonces, significaba un nuevo plan de estudios filosófico-teológicos para las universidades y un cultivo del buen gusto, para el publico en general. Este espíritu de Espejo aflora en obras como el "Nuevo Luciano de Quito o Despertador de los ingenios quiteños". "Marco Porcio Catón", "La ciencia blancardina", y las traducciones del "Tratado de lo maravilloso y lo sublime" de Dionisio Casio Longino y de la "Oración moderna de elocuencia" de Antonio Leonardo Thomás.

La crítica y la sátira "que ha sido del gusto del público": El desprecio de los detentadores de la cultura fue capeada por Espejo con la crítica al sistema jesuítico de enseñanza y, particularmente, con la crítica a Don Sancho de Escobar, orador sagrado famoso, epítome de la sabiduría y de las celebridades de los jesuitas en Quito. Con el mismo espíritu y objetivo, arremetió contra los "presumidos de doctos" que criticaron al anónimo autor de El Nuevo Luciano y, luego, a sectores del clero y la aristocracia, esos "lastimosos sabindojos" que tratarán de "envidioso" a Espejo. 
La desarticulación de los ardides de pensamiento de la burocracia y de sus cosmovisiones colonialistas y el despliegue investigativo y argumentativo que Espejo pone de relieve en "Defensa de los Curas de Riobamba", constituye una aplicación expresa de la razón y de la filosofía (puesto que siempre le guía la intención de llegar a las explicaciones globales y últimas) al objetivo de defender a los Curas de Riobamba, de sacar a luz los modos de deshumanización que se ejercía con los indígenas y de afirmar a la vez su propia humanidad y capacidad racional ${ }^{28}$.

La autovaloración y autoconciencia: Espejo deja ver la valoración de sí mismo, a pesar de la humillación social, en cartas y representaciones que escribió como respuesta o defensa frente a imputaciones y desacreditaciones que se vertieron en el juicio que María Chiriboga le puso a propósito de la ironía y las críticas vertidas en "Cartas riobambenses". La damisela riobambeña pidió en la demanda que el Betlemita José del Rosario informara todo lo que sepa y le conste acerca del "vilísimo nacimiento" de Espejo y acerca del "linaje, esfera y oficios ruines" de sus antepasados. Con una saña impropia de un religioso, el mencionado fraile, luego de informar con detalle lo solicitado en el juicio, concluyó que Espejo era el "más pernicioso e infame de (los) habitantes" de la Real Audiencia de Quito. Espejo respondió al religioso en términos que reflejan su conciencia de sí y para sí: "Si existo sobre la tierra, porque tuve progenitores, a ellos es que debo el ser, y a mí mismo, después de Dios, es que debo mi nobleza. Ocupaciones ilustres, pensamientos píos; educación cristiana, procedimientos públicos y privados de probidad y honor. Todo esto me ha elevado a un cierto grado de nobleza propia y adquirida que no puedo renunciar, sin hacerme indigno aun del nombre de racional" 29.

\footnotetext{
${ }^{28}$ En relación a los indígenas, Espejo captó lo verdaderamente esencial del problema: si éstos estaban fuera de la razón, de la economía, de la cultura, de la política, se debía, no a su condición humana inferior sino a su situación de conquistados. Era (y es) la opresión la que volvía sub-hombres a los hombres e imbéciles a los racionales. Pensar que en la condición humana de los indígenas radicaba la rusticidad, el salvajismo, la vagancia, la suciedad, etc., "es el error de gentes que no saben su idioma -dice Espejo-, sus usos y costumbres y es un absurdo político, filosófico y aun teológico, el mayor que puede escogitarse y es un oprobio de la humanidad pensar así... Fuera, pues, de nuestros escritos y papeles.las palabras instinto, rusticidad, imbecilidad, tontera y bobera de los indios": Defensa..., Escritos III, p. 226.

${ }^{29}$ Juicio de M. Chiriboga en contra de Espejo. Volumen de documentos sobre Espejo, Archivo
} 


\section{Filosofía aplicada a nivel social y cultural:}

Luego de su regreso de Bogotá, en 1790, Espejo muestra no solo una conciencia valorativa de sí mismo sino también una férrea convicción en torno a las posibilidades de lo "quiteño", del "genio quiteño", del "quiteñismo" en general. Esta contextualización debe ser leída, no como una estrechez de miras, sino como una reivindicación de la circunstancia propia y cercana. Durante muchos años ya, Espejo había desarrollado estrategias de humanización a través de la lucha por la racionalidad, la historicidad, etc. Hoy quiere sacar a luz "todo lo que el resto del mundo no se atreve todavía a creer de vosotros, esto es, que haya sublimidad en vuestros genios, nobleza en vuestros talentos, sentimientos en vuestro corazón y heroicidad en vuestros pechos". Manifiesto humanista éste que amplía a todos el derecho a la razón, que se consideraba privativo de los sectores hegemónicos: "Quiteños, les dice, sed los dispensadores del buen gusto, de las artes y de las ciencias...", porque "el genio quiteño lo abraza todo, todo lo penetra, a todo lo alcanza". Y concluye, lapidariamente: "La copia de luz que parece veo despedir de sí el entendimiento de un quiteño que lo cultivó, me deslumbra; porque el quiteño de luces para definirle bien, es el verdadero talento universal".

Una similar estrategia reivindicativa desplegará en "Primicias de la Cultura de Quito", el primer periódico quiteño, que Espejo pensaba utilizar como un instrumento que permitiera a sus coterráneos pasar "por grados desde la noche y tinieblas de la ignorancia y barbarie hasta la aurora y día de la ilustración" ${ }^{30}$. "Estamos en la agradable persuasión, dirá Espejo, de que los extraños que han tocado con sus manos los espíritus de Quito, si nos niegan amplitud de noticias, penetración de materias y grandeza de observaciones nos conceden ingenio, sagacidad, talentos y aptitud para entrar con decoro al palacio de las ciencias abstractas y naturales". La revalorización del carácter racional de sus compatriotas, la conciencia clara de las peculiaridades del quiteñismo y la fe absoluta en las posibilidades del genio quiteño, eran mecanismos idóneos para que todos se vieran a sí mismos, se valoraran, se elevaran de la barbarie a la civilización y promovieran la más decisiva de las

Nacional de Historia, Sección Cuenca, s. f.

${ }^{30}$ Espejo, Primicias de la Cultura de Quito, Escritos I, p. 4 
reivindicaciones humanas: la "introducción al templo suntuosísimo de nuestra alma, y por consiguiente al palacio de la verdadera sabiduría". "El conocimiento propio, dirá, es el origen de nuestra felicidad". En el autoconocimiento y en la autoconciencia, Espejo veía la salvación de sí mismo y de la patria ${ }^{31}$.

\section{Un problema existencial de nuestro tiempo examinado a la luz de las categorías de Eugenio Espejo}

En la casa donde el autor de este artículo arrienda un departamento, en un barrio popular de Quito, viven también otros arrendatarios de diversa procedencia. Junto a mi apartamento, vive una familia de indígenas otavaleños compuesta por la madre y dos hijos, un joven de 17 años y una adolescente de 16. La madre viste como indígena con los atuendos típicos de los otavaleños y no tiene interés alguno en ocultar o disimular su condición social, pero sus hijos visten como mestizos de clase media, por lo general con zapatos tenis, jean, camisa/blusa, sueter o chompa y el joven lleva casi siempre una gorra o boina que le permite recoger sin que los otros notaran su larga cabellera. Los otavaleños, por su cultura y tradiciones, no autorizan a sus miembros a cortarse el cabello como lo hacemos los mestizos. A veces, el joven recoge su cabellera en una cola de caballo al estilo de los mestizos que dejan crecer su cabellera. La adolescente no recoge su pelo al estilo de los otavaleños sino que lo deja suelto como lo hacen las mestizas. La madre se dedica a la venta de tejidos otavaleños (ponchos, chalinas, tapices, suéteres, alpargatas, etc.) y los jóvenes estudian en colegios de Quito, la capital de Ecuador. Los viernes a la tarde viajan todos a Otavalo, su lugar de origen y es entonces cuando surgen los problemas: la madre exige a sus hijos que se vistan como indígenas porque no pueden llegar a su tierra vestidos como mestizos. Cuando estoy en casa escucho los ecos de las difíciles discusiones entre la madre que les exige vestirse como otavaleños y sus hijos que se niegan a hacerlo. A la final la madre se impone, a la brava, y en muchas ocasiones, cuando salen al terminal a tomar el bus, he visto el

\footnotetext{
${ }^{31}$ Hegel, que posicionaría estos conceptos en la filosofía moderna, era, para entonces, apenas un jovenzuelo en Europa.
} 
desconcierto, la amargura, la indefinición y la vergüenza dibujados en sus rostros. A pesar que la sociedad ecuatoriana se ha abierto mucho en las dos o tres últimas décadas y va desapareciendo el prejuicio racial con respecto a los indígenas que existía antes, quedan todavía rezagos que dan lugar a comportamientos atípicos como los que acabo de narrar.

Como filósofo sé que estos jóvenes están dentro de un conflicto existencial que les amarga la vida: quieren ser lo que no son. Yo sé que en la historia de Ecuador y de América Latina hay una larga tradición de vilipendios injustificados contra los indígenas, una cadena de abusos, explotación y denigración que llevó a que los indígenas buscaran mecanismos de sobrevivencia y de resistencia contra el dominio, que consistían básicamente en volverse invisibles en términos ontológicos (aunque eran muy visibles como fuerza de trabajo) y en pasar desapercibidos para no ser denigrados, Su verdadero ser quedó recluido en algún repliegue de su alma y tuvieron que esperar cuatrocientos años para que el dominio, que pasó del campo a las ciudades, les dejara un segundo que fue aprovechado por ellos para verse, redescubrirse, valorarse, re-constituir su ser y sentirse al fin orgullosos de lo que son, de su cultura y de sus costumbres, Pero eso sucedió apenas en las tres últimas décadas del siglo XX. Ese fenómeno del colectivo indígena todavía no es plenamente asimilado por indígenas individuales que tratan de incorporarse a la vida de las ciudades: a nivel individual, ciertos indígenas siguen sintiendo vergüenza de presentarse como son y tratan de ocultarlo asimilándose a los mestizos. Es el caso de estos dos jóvenes del relato anterior. ¿Puede hacer algo la filosofía aplicada en este caso? ¿Podemos utilizar ahora las categorías desarrolladas hace dos siglos por Eugenio Espejo para esclarecer la cosmovisión y el conflicto existencial de estos jóvenes?

Durante la semana siguiente busco una oportunidad para hablar con la madre y sugerirle que podría ayudar a sus hijos a aceptar su condición de indígenas. “Usted es psicólogo?”, me pregunta y yo le explico que no, que soy filósofo y que la filosofía podría ayudarles a entenderse mejor a si mismos, puesto que el problema de sus hijos no es emocional sino un desajuste existencial con su propia identidad. La madre entiende de qué se trata y se demora una semana más en lograr que sus hijos acepten dialogar conmigo. Finalmente acceden y empezamos una serie de 
sesiones en las que aplico un método de esclarecimiento racional inspirado en los principios de Eugenio Espejo, nuestro indígena ilustrado del siglo XVIII. Al final de la primera sesión, ellos identifican su problema y lo definen como "vergüenza de dar a conocer su condición de indígenas con el objetivo de evitar el rechazo o desprecio de sus compañeros de colegio y de la sociedad mestiza en general". Una vez identificado el problema, me esfuerzo por conducir el diálogo de un modo que ellos lleguen por sí mismos a re-constituir su propia identidad, a verse y valorarse como indígenas, como sujetos-indígenas que tienen un valor humano similar a la de cualquier otro miembro de la sociedad (principio de subjetivación), a valorar sus formas de pensamiento, costumbres y tradiciones. Los diálogos siguientes avanzan en el sentido de que estos jóvenes se sientan parte de los procesos reivindicativos que los indígenas ecuatorianos y latinoamericanos llevaron adelante en las últimas décadas del siglo $\mathrm{XX}$, con ello re-constituyen su pertenencia a una historia colectiva de resistencia y reivindicación (principio de historicidad). Lo siguiente es que desarrollen una conciencia clara de su ubicación en un contexto de emergencia y re-valorización de sí mismos (principio de contextualización), de que asuman su vasta experiencia en la lucha por camuflarse y sobrevivir (principio de empiricidad), y de que tengan claros los objetivos de su lucha actual por ser reconocidos como indígenas (principio de dignidad). Los jóvenes perciben de esta manera que sus propios desarrollos étnicos les han llevado a la coyuntura actual de elegir entre la autenticidad de su condición de indígenas o la farsa de su imitación del modo de ser mestizo (principio de libertad). Encuentran en el diálogo y en el proceso de esclarecimiento suficientes razones para sentirse orgullosos de ser lo que son y como son y para percibirse como elementos fundamentales de la realidad social ecuatoriana con los mismos derechos y obligaciones que el resto de ecuatorianos (principio de pertenencia). Finalmente, encuentran dentro de sí mismos motivos y razones para coincidir consigo mismos y para sentirse satisfechos con su propia identidad (principios de gloria -en sentido ilustrado- y de felicidad).

Estos jóvenes indígenas han realizado por sí mismos, con ayuda de un orientador filosófico, un esclarecimiento racional de los fundamentos ontológicos, antropológicos, éticos y políticos que sostienen su existencia 
más allá de los prejuicios o equívocos los obnubilaban y atormentaban. Estos dos jóvenes encuentran al fin suficiente sustento en sí mismos, en lo que son y en lo que valen, como para encontrar que ya no es necesario ocultar su condición de indígenas ni imitar los modos mestizos de ser. Estos jóvenes han encontrado en el proceso reflexivo que el reconocimiento y la aceptación de sí mismos son suficientes para encontrar el los demás el respeto a lo que son y como son, Al cabo de diez sesiones de diálogo esos dos jóvenes han descubierto que tiene pleno sentido el mostrar lo que son y como son, sin vergüenza, sin atavismos, sin reservas, sin ocultamientos. Se sienten al fin identificados consigo mismos y han desarrollado una conciencia de sí que los capacita para verse, valorarse y superar los traumas que una larga historia de dominio pudo haber dejado en su conciencia colectiva. Luego de esta toma de conciencia de sí mismos, los jóvenes empiezan a vestir sus ropas tradicionales, no solo los viernes cuando van a sus comunidades de origen, sino todos los días, cuando se quitan los uniformes del colegio. Se han vuelto mejores hijos y ayudan a su madre en su lucha diaria por obtener el dinero necesario para la supervivencia y la educación. La madre, que ha percibido el cambio de sus hijos, me agradece la ayuda brindada y yo, filósofo, siento por fin que la filosofía sirve para algo.

\section{Conclusión}

Hemos visto cómo Eugenio Espejo, un personaje de oscuro nacimiento, en una lejana colonia, luchó durante su vida con los mecanismos de la razón y la filosofía contra el sistema de dominio que cosificaba a los dominados, los expulsaba del ámbito de la razón y los bestializaba. Ese personaje se atrevió a desafiar al sistema insertándose subrepticiamente y posicionándose en el ámbito de la filosofía, las ciencias, la razón. Esto que ahora parece tan natural, estaba vedado para los indios y mestizos en tiempos del coloniaje español en América. Acceder al uso de la razón era, pues, un atentado. Espejo y quienes lucharon por la independencia de inicios del siglo XIX, consideraron la conquista de la razón como necesaria para mirarse como seres humanos, capaces de acceder al conocimiento, a la filosofía, a las ciencias, al buen gusto y a las artes. Ese 
era su modo de re-constituir el rango humano del que se les había expulsado y de demostrarse a sí mismos y a los demás que eran hombres, racionales, dignos de sí mismos y de alma libre. Sin esta conciencia valorativa de sí mismos difícilmente habrían podido encarar las luchas de independencia, a partir de 1809. La circunstancia histórica hizo que Espejo desarrollara un concepto de filosofía que bien podría figurar como un hito en la historia de la filosofía aplicada y de la orientación filosófica. Él sostuvo: "Siempre sirvió la filosofía a pensar con rectitud, a moderar los ciegos impulsos de la ciega imaginación, a corregir los errores del entendimiento" ${ }^{32}$.

\section{Bibliografía}

Casas, Bartolomé de las, Brevísima relación de la destrucción de las Indias, Ediciones Orbis, Barcelona, 1986,

Espejo, Eugenio, Obras completas, Casa de la Cultura Ecuatoriana, Quito, 2008, 4 vols.

Freile, Carlos, Eugenio Espejo, filósofo, Universidad San Francisco de Quito - Ediciones ABYA-YALA, Quito, 1997, 393 ps.

Guerra Bravo, Samuel: "Espejo, pensador filosófico", en Latinoamérica. Anuario de Estudios Latinoamericanos, UNAM, México, 1978, ps. 245267. "Cartas desde el destierro" en Revista Cultura, $\mathrm{N}^{\circ}$ 10, Banco Central del Ecuador, Quito, 1981.

Gerbi, Antonello, La disputa del nuevo mundo. Historia de una polémica 1750-1900, México/Buenos Aires, 1960.

Lewis Hanke, El prejuicio racial en el nuevo mundo. Aristóteles y los indios de Hispanoamérica, Sep/Setentas, México, 1974, 206 ps.

Keeding, Ekkehart, Surge la nación. La ilustración en la Audiencia de Quito, Banco Central del Ecuador, Quito, 2005, 690 ps.

Naranjo, Plutarco y Fierro, Rodrigo, Eugenio Espejo: su época y su pensamiento, Universidad Andina Simón Bolívar - Corporación Editora Nacional, Quito, 2008

\footnotetext{
32 "Marco Porcio Catón" en Escritos del doctor Francisco Javier Eugenio Santa Cruz y Espejo, Vol. III, Quito, 1923, p. 275.
} 
Núñez Jorge (Comp.), Eugenio Espejo y el pensamiento precursor de la independencia, ADHILAC, Quito, 1992, 272 ps.

Paladines, Carlos (Edit.), Juicio a Eugenio Espejo, Casa de la Cultura Ecuatoriana, Quito, 2007, 265 ps.

Roig, Arturo Andrés, Humanismo en la segunda mitad del siglo XVIII, Banco Central del Ecuador-Corporación Editora Nacional, Quito, 1984, 2 vols.

VV. AA., Espejo: Conciencia crítica de su época, Ediciones de la Universidad Católica, Quito, 1978, 369 ps.

Villalba, Jorge (Edit.), Las prisiones del Doctor Eugenio Espejo: 1783, 1787, 1795, Ediciones de la Pontificia Universidad Católica del Ecuador, Quito, 1992, 187 ps. 



\section{NOTAS Y EVENTOS/ COMMENTARIES AND REPORTS}


